\title{
Diabetes mellitus in patients with cystic fibrosis*
}

\author{
Crésio de Aragão Dantas Alves', Renata Arruti Aguiar², Ana Cláudia S Alves², Maria Angélica Santana ${ }^{3}$
}

\begin{abstract}
Cystic fibrosis-related diabetes (CFRD) is the principal extra-pulmonary complication of cystic fibrosis, occurring in 15-30\% of adult cystic fibrosis patients. The number of cystic fibrosis patients who develop diabetes is increasing in parallel with increases in life expectancy. The aim of this study was to review the physiopathology, clinical presentation, diagnosis and treatment of CFRD. A bibliographic search of the Medline and Latin American and Caribbean Health Sciences Literature databases was made. Articles were selected from among those published in the last twenty years. Insulin deficiency, caused by reduced $\beta$-cell mass, is the main etiologic mechanism, although insulin resistance also plays a role. Presenting features of type 1 and type 2 diabetes, CFRD typically affects individuals of approximately 20 years of age. It can also be accompanied by fasting, non-fasting or intermittent hyperglycemia. Glucose intolerance is associated with worsening of nutritional status, increased morbidity, decreased survival and reduced pulmonary function. Microvascular complications are always present, although macrovascular complications are rarely seen. An oral glucose tolerance test is recommended annually for patients $\geq 10$ years of age and for any patients presenting unexplained weight loss or symptoms of diabetes. Patients hospitalized with severe diseases should also be screened. If fasting hyperglycemia persists for more than $48 \mathrm{~h}$, insulin therapy is recommended. Insulin administration remains the treatment of choice for diabetes and fasting hyperglycemia. Calories should not be restricted, and patients with CFRD should be managed by a multidisciplinary team.
\end{abstract}

Keywords: Cystic fibrosis; Diabetes mellitus.

\footnotetext{
* Study carried out at the Faculdade de Medicina da Universidade Federal da Bahia - UFBA, Federal University of Bahia School of Medicine - Salvador (BA) Brazil.

1. Professor and Head of the Pediatric Endocrinology Residency Program at the Universidade Federal da Bahia - UFBA, Federal University of Bahia - School of Medicine, Salvador (BA) Brazil.

2. Resident (R3) in Pediatric Endocrinology at the Professor Edgard Santos University Hospital of the Universidade Federal da Bahia - UFBA, Federal University of Bahia - Salvador (BA) Brazil.

3. Pulmonologist and Coordinator of the Cystic Fibrosis Department of the Octávio Mangabeira Hospital, Bahia State Department of Health - Salvador (BA) Brazil. Correspondence to: Crésio de Aragão Dantas Alves. Rua Plínio Moscoso, 222, apto. 601, CEP 40157-190, Salvador, BA, Brasil.

Phone 5571 3281-6374. E-mail: cresio.alves@uol.com.br

Submitted: 21 August 2006. Accepted, after review: 25 August 2006.
} 


\section{Introduction}

Cystic fibrosis (CF) is an autosomal recessive genetic disease, with an incidence of 1:2500 live births in Caucasian populations..$^{(1-3)}$ It is estimated that there are $2000 \mathrm{CF}$ patients in Brazil. ${ }^{(4)}$ It is a complex, severe disease that involves various organic systems. Its classic clinical presentation consists of chronic obstructive pulmonary disease, exocrine pancreatic insufficiency and sweat chloride levels higher than $60 \mathrm{mEq} / \mathrm{L}^{(5)}$ Over 1000 mutations in The CF gene is located on the long arm of chromosome 7. To date, more than $1000 \mathrm{CF}$ gene mutations have been identified. ${ }^{(2,4)}$ Mutation $\Delta \mathrm{F} 508$ is the most common, identified in $60-70 \%$ of patients and correlated with exocrine pancreatic insufficiency. ${ }^{(6)}$ These mutations alter the encoding of a transmembrane protein known as the cystic fibrosis transmembrane regulator (CFTR), resulting in chloride channel dysfunction. ${ }^{(3)}$ Alterations in chloride and water transport result in viscous secretions with progressive obstruction and occasional destruction of organs. Interactions among genetic mutations, modifying genes, as well as environmental factors, contribute to the wide phenotypical variability and severity of the disease.(7) Pulmonary infections and their complications account for 90\% of CF-related morbidity and mortality. ${ }^{(6)}$ The longest survival is related to the treatment of meconium ileus (if present) at birth, proper nutritional support, respiratory physiotherapy, and early antibiotic therapy for pulmonary infections. ${ }^{(6)}$

Increased longevity has led to a greater incidence of extra-pulmonary complications, chief among which cystic fibrosis-related diabetes (CFRD). ${ }^{(1,2)}$ It is estimated that CFRD affects approximately 15-30\% of adults with CF. ${ }^{(3,8)}$ The objective of this study was to review recent knowledge on CFRD, especially regarding the physiopathology, clinical profile, morbidities, diagnosis and treatment regimen.

\section{Pathophysiology}

In CF, the glucose metabolism is influenced by malnutrition, infections (chronic and acute), increased basal metabolism, glucagon deficiency, pancreatic polypeptide dysfunction, altered insulin clearance, alterations in the intestinal transit (including poor absorption), liver dysfunction, and increased respiratory effort. ${ }^{(9-11)}$ The physiopathology of CFRD differs from that of type 1 diabetes (DM1) and type 2 diabetes (DM2). It is classified by the American Academy of Diabetes under 'other types of diabetes', listed as being 'caused by exocrine pancreatic lesion, ${ }^{(1-12)}$ Although insulin deficiency is the principal mechanism, insulin resistance is also part of the etiopathogenesis of CFRD. ${ }^{(13,14)}$

\section{Insulinopenia}

Chloride channel alterations lead to hyperviscosity of pancreatic duct secretion, causing obstructive lesions, fat cell infiltration and progressive islet fibrosis, as well as reduced secretion of insulin, glucagon, and pancreatic polypeptide..$^{(10,14)}$ The $\beta$-cell accumulation of amyloid substance, which is seen in patients with CF and diabetes although not in those without diabetes, has a cytotoxic inhibitory effect on insulin secretion, thereby leading to insulinopenia. ${ }^{(1,13)}$ Some authors reported the presence of anti-islet antibodies, whereas others have failed to find any autoimmune factors. ${ }^{(11)}$ Others found greater prevalence of antibodies against Pseudomonas, suggesting an immunological mechanism triggered by bacterial pulmonary infections. ${ }^{(15)}$ Associations with the histocompatibility leukocyte antigens DR3 and DR4, common in patients with DM1, have not been described. ${ }^{(16)}$

Decreased insulin secretion has been associated with exogenous pancreatic insufficiency. ${ }^{(1,17)}$ Patients with $\mathrm{CF}$ and exocrine pancreatic insufficiency present a $41 \%$ reduction in the plasma insulin peak in response to glucose ingestion, as well as a delay in the time required to reach this peak. ${ }^{(1)}$ One group of authors demonstrated that the time needed to reach the insulin peak after glucose ingestion was 20-60 min for the control group, 30-120 min for the CF patients with normal glucose tolerance, 60-120 min for the CF patients with glucose intolerance, and $150 \mathrm{~min}$ for those with CFRD. ${ }^{(18)}$ Insulin response to oral glucose has been shown to correlate positively with peptide-C concentration after venous infusion of glucagon. This measurement estimates residual $\beta$-cell function in patients with CFRD. ${ }^{(11)}$ Due to this delay in insulin response, some patients can present hyperglycemia or hypoglycemia. ${ }^{(1)}$

\section{Insulin resistance}

The role of insulin resistance in the physiopathology of CFRD has yet to be clarified. When 
present, insulin resistance is related to various mechanisms, including respiratory infections (chronic or recurrent), corticosteroid treatment, subclinical liver fibrosis, increased serum levels of counter-regulatory hormones (e.g., catecholamines and cortisol), increased cytokines (e.g., interleukin 1 and 6), and glucotoxicity. ${ }^{(19,20)}$ Elevated levels of tumor necrosis factor alpha (TNF- $\alpha)$ is directly related to the level of glucose tolerance. ${ }^{(21)}$ Patients with normal glycemic levels tend to present a less elevation of TNF- $\alpha$ levels than do those who are glucose intolerant. Ofei et al. (1996) demonstrated increased insulin sensitivity in patients with DM2 after the infusion of synthetic antibodies against TNF- $\alpha .^{(22)}$

Insulin resistance can also be caused by alterations in the glucose transporter protein 4 (GLUT4). The translocation of GLUT4 from the intracellular compartment to the surface is necessary for the normal transport of glucose into the cell. ${ }^{(23)}$ Depending on the type of mutation, the CFTR can be deficient or not produced at all. ${ }^{(23)}$ There is evidence that abnormalities in this protein can alter the translocation of GLUT4 from the intracellular environment to the plasma membrane, contributing to insulin resistance. ${ }^{(23)}$

The best method of evaluating insulin resistance is the normoglycemic hyperinsulinemia technique, which consists of the simultaneous infusion of insulin and glucose. If hepatic glucose production is inhibited by insulin infusion, the quantity of exogenous glucose needed to maintain normoglycemia will reflect the degree of peripheral tissue insulin sensitivity. ${ }^{(1)}$ Peripheral insulin resistance (IR) can also be more easily evaluated by the Homeostasis Model Assessment index, in which $\mathrm{IR}=$ [fasting insulin $\times$ fasting glucose/22.5] ${ }^{\left({ }^{(10)}\right.}$

\section{Morbidity and mortality}

One study showed that survival to the age of 30 in patients with CF without diabetes is $60 \%$, compared with $25 \%$ in patients with CFRD. ${ }^{(24)}$ In addition to a risk of death 6-times greater than that of CF patients without diabetes, ${ }^{(1)}$ the principal morbidities observed in these patients are as described in the following sections.

\section{Respiratory effects}

Patients with CFRD, when compared with CF patients without diabetes, present worse pulmonary function, pulmonary exacerbations that are more severe/frequent, and greater prevalence of pathogenic bacteria in sputum samples; consequently, CFRD patients have lower survival and worse quality of life. ${ }^{(8,9)}$ On group of authors showed that the degree of glucose intolerance correlates directly with lower forced expiratory volume in one second and lower forced vital capacity. ${ }^{(25)}$ Other authors, analyzing sputum samples, found a high prevalence of Staphylococcus aureus, Pseudomonas aeruginosa, Burkholderia cepacia, Stenotrophomonas maltophilia and Aspergillus spp. ${ }^{(9)}$ Those authors reported that asthma and sinusitis were more common in patients with CFRD than in CF patients without diabetes.

The decline in pulmonary function starts 2-4 years before the diagnosis of diabetes, and is related to the level of glucose intolerance, thus promoting alteration in the structure of the pulmonary tissue and predisposing patients to infections. ${ }^{(3,25)}$ Since insulin is an anabolic hormone responsible for protein metabolism, insulin deficiency reduces inspiratory and diaphragm muscle function, further worsening pulmonary function. ${ }^{(1,8)}$

Treatment for CFRD reverses the decline in pulmonary function, suggesting that it actually contributes to the progression of the disease and is not merely one of its markers. ${ }^{(26)}$

\section{Nutritional effects}

Patients with CF generally present poor digestion and poor absorption, which become clinically apparent after the destruction of approximately 90\% of the exocrine pancreas. In this situation, patients present frequent, voluminous, grey, foul-smelling, occasionally greasy, stools. ${ }^{(27)}$ Flatulence and abdominal distention are common. Poor absorption is reflected in the nutritional status, with proteincalorie malnutrition, vitamin deficiency and stunted growth (weight and height). The clinical profile can evolve to overall deficiency, including muscle hypotrophy, despite normal appetite and food intake. There is a consistent association between the severity of the pulmonary disease and the nutritional status. The development of cellular immunodeficiency secondary to malnutrition results in greater susceptibility to infections. ${ }^{(27)}$ Insulin deficiency in combination with CFRD results in poor nutritional status, since insulin is an anabolic hormone. ${ }^{(28)}$ Patients with CFRD present lower height and weight 
for their age, as well as lower body mass index, than do individuals with CF without diabetes. ${ }^{(9)}$ Protein catabolism improves with early insulin therapy. ${ }^{(29)}$

\section{Psychosocial effects}

The occurrence of CFRD further increases the severity of CF, due to the need to use insulin injections and monitor capillary glycemia, as well as to dietary restrictions and hospitalizations due to uncontrolled metabolism. Multidisciplinary support is fundamental to accepting this new problem and its subsequent limitations..$^{(2,30,31)}$

Since patients with CFRD are typically teenagers or young adults, a psychosocial approach can be more difficult. They often stop monitoring glycemia and do not take their insulin regularly. ${ }^{(30)} \mathrm{A}$ negative attitude toward life and the lack of concrete objectives indicate a clinical profile of depression that must be dealt with by a specialist. ${ }^{(24)}$ The positive aspects of this relationship are self-confidence, self-esteem, and family support. The negative aspects are family conflicts, lack of communication with parents, depression, and refusal to accept the disease. ${ }^{(2)}$

\section{Microvascular and macrovascular effects}

Microvascular complications are potentiated by the use of nephrotoxic antibiotics and anti-inflammatory drugs, as well as by vitamin deficiency. ${ }^{(3,32)}$ Other factors associated with the development of microangiopathic complications include duration of the disease and glycemic control. ${ }^{(32)}$

The reported rates of microvascular complications in CFRD are as follows: retinopathy (5-16\%); neuropathy (5-21\%); and nephropathy (3-16\%). ${ }^{(14)}$ Retinopathy is diagnosed through dilated eye exam. There is no reliable method of performing triage of diabetic nephropathy in these patients. Microalbuminuria, the gold standard in other types of diabetes, is rarely indicated in CFRD, since the urinary excretion of albumin is increased due to chronic infections and prolonged recurrent use of aminoglycosides. ${ }^{(33)}$ Diabetic neuropathy is evaluated through skin sensitivity and tendon reflexes. In CFRD, it can be aggravated by liposoluble vitamin deficiency. ${ }^{(13)}$

There are few reports of macrovascular complications. Possible explanations include low life expectancy, lower incidence of dyslipidemia, hypertension, insulinopenia, and the absence of obesity. ${ }^{(3,34)}$ There is no recommendation for the triage of these complications, although a fasting lipid profile is indicated. ${ }^{(3)}$

\section{Clinical profile}

Mean age at the onset of CFRD is 18-21 years, and the disease affects 15-30\% of adult CF patients. ${ }^{(1,33)}$ Although more rarely, suckling infants can also present this complication. ${ }^{(35)}$ The principal risk factors associated with the development of CFRD are increased longevity, female gender, exogenous pancreatic insufficiency, homozygosity for the $\Delta$ F508 mutation, pulmonary infections, treatment with corticosteroids, requiring enteral or parenteral nutrition, and pregnancy. ${ }^{(9,11,13)}$

The characteristics of both DM1 and DM2 are present in CFRD. ${ }^{(2,3,9)}$ The clinical evolution is insidious. Initial postprandial hyperglycemia evolves to fasting hyperglycemia. Sometimes, hyperglycemia only occurs during periods of stress. ${ }^{(3,12)}$ Ketoacidosis is uncommon..$^{(13,36)}$ In addition to polyuria, polydipsia, and weight loss, classic symptoms of DM1, nonspecific manifestations such as reduction in the rate of growth, delayed pubertal development and unexplained decline in pulmonary function suggest the diagnosis. ${ }^{(3)}$ Diabetes can occasionally be the first manifestation of $\mathrm{CF}^{\left({ }^{(37)}\right.}$ The weight loss, drop in the body mass index and decline in pulmonary function begin up to 4.5 years prior to the diagnosis of diabetes. ${ }^{(3,25)}$ Physicians should not wait for the occurrence of classical symptoms to consider the diagnosis, since delayed treatment is associated with greater morbidity. ${ }^{(34,38)}$ Table 1 compares CFRD clinical profile with DM1 and DM2.

\section{Classification}

Glucose metabolism alterations in CF patient with CF can be didactically classified as follows: 1) glucose intolerance; 2) diabetes without fasting hyperglycemia; 3) diabetes with fasting hyperglycemia; and 4) intermittent diabetes, which occurs during periods of infection, hospitalizations, use of enteral or parenteral nutrition and treatment with corticosteroids. ${ }^{(2,3)}$

Mean prevalence of these disturbances in adults with $\mathrm{CF}$ is as follows: glucose intolerance $=35 \%$; 
CFRD without fasting hyperglycemia $=25 \%$; and CFRD with fasting hyperglycemia $=15 \%{ }^{.39)}$

\section{Diagnosis}

The diagnosis of the various levels of glucose intolerance is based on fasting glycemia or on the oral glucose tolerance test (OGTT). Although fasting glycemia is easier to perform, it has low sensitivity because there are clinical forms that do not present fasting hyperglycemia. ${ }^{(3,30)}$ Therefore, the OGTT is recommended as gold standard. It is performed after the ingestion of $1.75 \mathrm{~g} / \mathrm{kg}$ of glucose (maximum: $75 \mathrm{~g}$ ), measuring basal glycemia and glycemia after $2 \mathrm{~h}$. In order to be submitted to this test, the patient cannot be undergoing treatment with corticosteroids and cannot have had a pulmonary infection within the preceding month. ${ }^{(3)}$ Abnormal results must be confirmed by a second test, principally in asymptomatic patients. ${ }^{(40)}$ Patients with fasting glycemia $\geq 126 \mathrm{mg} / \mathrm{dL}$ do not need to be submitted to the OGTT. Table 2 shows the diagnostic criteria for CFRD and glucose intolerance.

\section{Triage}

Triage must be performed annually for patients $\geq 10$ years of age, using the 0GTT. ${ }^{(1,13,34)}$ It should also be performed for patients of any age who are hospitalized for severe diseases, receiving enteral or parenteral nutrition (intermittent CFRD), presenting unexplained weight loss or having symptoms of diabetes. ${ }^{(41)}$

The glycosylated hemoglobin test ( $\mathrm{HbA} 1 \mathrm{c})$ is not an appropriate triage method, because artificially low or normal values can result from intermittent hyperglycemia or high turnover of red blood cells due to hypoxia, chronic inflammation, and altered glycation processes. ${ }^{(3)}$ Performing an HbA1c every three months is useful for monitoring pre-existing CFRD. ${ }^{(11)}$

\section{Treatment}

The treatment for CFRD is aimed at the management of hyperglycemia, prevention of hypoglycemia and optimization of the nutritional status, as well as the promotion of social and emotional adapta-

Table 1 - Clinical, epidemiological, etiological and therapeutic aspects of CFRD, DM1, and DM2. Adapted from Dobson et al., 2004 ${ }^{(14)}$ and Costa et al., 2005. ${ }^{(3)}$

\begin{tabular}{|c|c|c|c|}
\hline Characteristics & CFRD* & $\mathrm{DM} 1^{*}$ & $\mathrm{DM} 2^{*}$ \\
\hline Age at onset (years) & $\sim 20$ & $<20$ & $>40$ \\
\hline Prevalence & $\begin{array}{l}5-10 \% \text { of the } \\
\text { patients with } \mathrm{CF}^{*}\end{array}$ & $\begin{array}{l}\text { 0.5- } 0.7 \% \text { of } \\
\text { the general population }\end{array}$ & $\begin{array}{l}5-7 \% \text { of } \\
\text { the general } \\
\text { population }\end{array}$ \\
\hline Body mass index & Thin & Thin-Normal & Overweight-Obesity \\
\hline Insulinopenia & Progression to $\downarrow \downarrow \downarrow$ & $\downarrow \downarrow \downarrow$ & $\begin{array}{c}\downarrow \text { in the first phase, } \\
\text { possible progression to } \downarrow \downarrow\end{array}$ \\
\hline Insulin resistance & Normal or $\uparrow$ & Normal or $\uparrow$ & 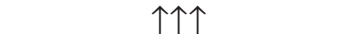 \\
\hline $\begin{array}{l}\text { Exocrine pancreatic } \\
\text { insufficiency }\end{array}$ & Yes & No & No \\
\hline Autoimmunity & No & Yes & Rare \\
\hline Association with HLAs* & No & Yes & No \\
\hline Amyloid deposition & Yes & No & Yes \\
\hline Ketoacidosis & Rare & Yes & Rare \\
\hline $\begin{array}{l}\text { Microvascular } \\
\text { complications }\end{array}$ & Yes & Yes & Yes \\
\hline $\begin{array}{l}\text { Macrovascular } \\
\text { complications }\end{array}$ & No (?) & Yes & Yes \\
\hline Treatment & $\begin{array}{c}\uparrow \text { Calorie intake; } \\
\text { insulin; use of controversial } \\
\text { oral hypoglycemic agents }\end{array}$ & $\begin{array}{l}\text { Age-appropriate } \\
\text { calorie intake; } \\
\text { insulin }\end{array}$ & $\begin{array}{l}\text { Calorie restriction; } \\
\text { oral hypoglycemic agents } \\
\text { or insulin }\end{array}$ \\
\hline
\end{tabular}

"CF: cystic fibrosis; CFRD: cystic fibrosis-related diabetes; DM1: type 1 diabetes; DM2: type 2 diabetes; HLAs: histocompatibility leukocyte antigens. 
Table 2 - Criteria used in the diagnosis and classification of cystic fibrosis-related diabetes.

\begin{tabular}{lcc}
\hline \multicolumn{1}{c}{ Classification } & Fasting blood glucose $(\mathrm{mg} / \mathrm{dL})$ & Blood glucose $2 \mathrm{~h}$ after OGTT $(\mathrm{mg} / \mathrm{dL})$ \\
\hline Normal glucose tolerance & $70-99$ & $<140$ \\
Glucose intolerance & $100-125$ & $140-199$ \\
$\begin{array}{l}\text { DM without fasting } \\
\text { hyperglycemia }\end{array}$ & $<126$ & $\geq 200$ \\
$\begin{array}{l}\text { DM with fasting } \\
\text { hyperglycemia }\end{array}$ & $\geq 126$ & $\geq 200$ \\
lntermittent DM & $\geq 126$ during infections, enteral nutrition and & $\geq 200$ during infections, enteral \\
& use of corticosteroids & nutrition and use of corticosteroids \\
\hline
\end{tabular}

OGTT: oral glucose tolerance test; DM: diabetes mellitus. OGTT is not necessary when fasting glycemia is already a diagnosis of diabetes.

tion. ${ }^{(28)}$ The approach must be individualized, with emphasis on the clinical and severity aspects of each case, and managed by a multidisciplinary team. Education, awareness, and parental cooperation are important elements in the establishment of mutual trust, with the objective of treating the disease early and appropriately. ${ }^{(27)}$ There are no specific recommendations as to the treatment of patients with glucose intolerance. Table 3 summarizes the principal therapeutic recommendations.

\section{Nutritional approach}

A balanced, high-caloric, high-protein diet, with normal to high lipid content, is recommended.
Restrictive diets are inappropriate, since malnutrition results in worsening of the overall health status, higher recurrence of infections, and premature death. ${ }^{(1)}$ Maintaining the caloric intake at 30-50\% above daily recommendations is necessary due to the excessive energy expenditure.(3) ${ }^{(3)}$ protein content of the diet should be 2 to 3 times above normal. Fats should be offered without restriction, and should constitute $30-40 \%$ of the overall diet. ${ }^{(41)}$ Liposoluble vitamins (D, E, and $\mathrm{A}$ ) are indicated for pancreatic insufficiency, and vitamin K supplementation is recommended for patients with liver disease. ${ }^{(13)}$ No salt restriction is indicated, and sodium intake should average over $4000 \mathrm{mg} /$ day.

Table 3 - Outpatient treatment of cystic fibrosis-related diabetes and glucose intolerance. Adapted from Moran, 2000. ${ }^{(41)}$

\begin{tabular}{|c|c|c|c|c|}
\hline \multirow[t]{2}{*}{ Recommendations } & \multicolumn{3}{|c|}{ CFRD } & \multirow[t]{2}{*}{ Glucose intolerance } \\
\hline & $\begin{array}{l}\text { With fasting } \\
\text { hyperglycemia }\end{array}$ & $\begin{array}{l}\text { Without fasting } \\
\text { hyperglycemia }\end{array}$ & intermittent & \\
\hline Insulin & Yes & $?$ & $\begin{array}{c}\text { Yes: during episodes } \\
\text { of hyperglycemia }\end{array}$ & No \\
\hline $\begin{array}{l}\text { Oral hypoglycemic } \\
\text { agents }\end{array}$ & No & $?$ & No & No \\
\hline Diet & $\begin{array}{c}\text { Hypercaloric, greater } \\
\text { fat and sodium input, } \\
\text { without carbohydrate } \\
\text { restrictions }\end{array}$ & $\begin{array}{c}\text { Avoid carbohydrate } \\
\text { overload }\end{array}$ & $\begin{array}{l}\text { Hypercaloric, } \\
\text { greater fat and } \\
\text { sodium intake, no } \\
\text { carbohydrate } \\
\text { restrictions }\end{array}$ & $\begin{array}{c}\text { Avoid carbohydrate } \\
\text { overload }\end{array}$ \\
\hline Capillary glycemia & $\begin{array}{l}\text { 4×/day, } \\
\text { every day }\end{array}$ & $\begin{array}{c}\text { 4×/day, } \\
\text { once/month }\end{array}$ & $\begin{array}{l}4 \times / \text { day and during } \\
\text { periods of stress }\end{array}$ & No \\
\hline $\begin{array}{l}\text { Endocrinologist } \\
\text { appointment }\end{array}$ & Every 3 months & Annually & $\begin{array}{c}\text { When } \\
\text { stress-related } \\
\text { hyperglycemia } \\
\text { occurs }\end{array}$ & $\begin{array}{l}\text { Once for education } \\
\text { and orientation. } \\
\text { Other appointments } \\
\text { if necessary }\end{array}$ \\
\hline
\end{tabular}

CFRD: cystic fibrosis-related diabetes. 
Counting carbohydrates is indicated, not as a restriction but as a means of controlling glucose levels. ${ }^{(1)}$ Dietary planning should include recommendations regarding diet management during exercise, diseases, and episodes of hypoglycemia.

If weight or pubertal development cannot be guaranteed through an adequate diet or oral supplementation, feeding via nasogastric tube, gastrostomy or jejunostomy should be considered. ${ }^{(13)}$ Parenteral nutrition is recommended for severe diseases, for pancreatitis and after abdominal surgery. ${ }^{(13)}$

\section{Pharmacological approach}

There is no consensus regarding routine pharmacotherapy for individuals with glucose intolerance or for CFRD patients without fasting hyperglycemia. In these situations, insulin is recommended for patients presenting symptoms of diabetes, unexplained weight loss or a decline in pulmonary function. ${ }^{(19)}$ Some authors believe that such patients can benefit from early treatment and recommend treatment in the prediabetes phase. ${ }^{(42)}$

Insulin is the only pharmacological treatment recommended for patients with CFRD and fasting hyperglycemia. ${ }^{(19)}$ The use of insulin improves nutritional status and pulmonary function, in addition to controlling glycemia. ${ }^{(1,42)}$ Flexibility in the insulin regimen is recommended. The best option seems to be the use of fast-acting or ultrafast-acting insulin (e.g., Lispro and Aspart) before meals, calculating the dose according to the carbohydrate count (1 unit for each 15-40 g of carbohydrates). Due to the alterations in food intake, poor intestinal absorption, and recurrent infections, intermediateacting insulin, neutral protamine Hagedorn, and slow-acting analogs (Glargine, Detemir, etc.) should not be used, or should be used in low, nocturnal doses, for patients with fasting hyperglycemia. ${ }^{(8,41)}$ Patients using nocturnal enteral or parenteral nutrition need specific insulin regimens in order to avoid hyperglycemia during diet infusion. ${ }^{(13)}$ Insulin doses also need to be adjusted during pulmonary infections, hospitalizations, fever and corticosteroid use. ${ }^{(11)}$ In those cases, patients develop insulin resistance, requiring patients who use insulin regularly to increase the dosage and precipitating fasting hyperglycemia in patients with intermittent CFRD or CFRD without fasting hyperglycemia. Hospitalized patients whose fasting hyperglycemia persists for over $48 \mathrm{~h}$ need insulin therapy until their condition improves and glycemic levels return to normal. ${ }^{(28)}$ Glycemic control acquired through insulin infusion pump therapy was evaluated by other authors, who did not make a formal recommendation regarding its use. ${ }^{(2)}$ Continuous monitoring of serum glycemia would be the ideal method to evaluate glucose variations. Although this method is available, it is still underused due to resistance on the part of patients, who refuse to wear the monitors. Periodical determination of fasting and postprandial serum glycemia is the method of choice. It should be evaluated more frequently during acute infections or corticosteroid use. ${ }^{(3)}$ Glycemic objectives are as follows: 70-140 mg/dL before meals and 100-180 mg/dL postprandially. ${ }^{(12)}$ More recently, continuous glucose monitoring has made it possible to identify relevant glycemic variations not apparent during conventional glycemia measurement. ${ }^{(14)}$

Oral hypoglycemic agents are not recommended in the treatment for CFRD, except in the context of medical research. ${ }^{(3,12)}$ Sulfonylurea can be a therapeutic option for patients with diabetes who retain $\beta$-cell function, since it increases insulin secretion. ${ }^{(3)}$ Side effects include hypoglycemia, liver toxicity, and inhibition of CFTR function, since this protein is believed to be a sulfonylurea receptor. ${ }^{(3)}$ Glinides, which also stimulate insulin secretion, can be a choice for patients without fasting hyperglycemia. ${ }^{(3)}$ Their principal adverse effects are mild hypoglycemia, transitory visual disturbances, and gastrointestinal alterations. When compared to lispro insulin, repaglinide was less efficacious in the control of postprandial glycemia. ${ }^{(39)}$ Metformin, whose principal effect is to reduce insulin resistance, is contraindicated, since it exacerbates gastrointestinal alterations and increases the risk of lactic acidosis in patients with respiratory insufficiency. ${ }^{(3,14)}$ Thiazolinediones (known commercially as glitazones), which also reduce peripheral insulin resistance, present a high level of hepatotoxicity, and are therefore not recommended. ${ }^{(14)}$ Acarbose, despite reducing postprandial glycemia, is associated with adverse gastrointestinal effects. ${ }^{(3,14)}$

\section{Conclusion}

The development of CFRD is a significant complication of CF. Although it is principally caused by insulinopenia, insulin resistance is also involved. 
Female patients, homozygous for $\Delta \mathrm{F} 508$, and patients with severe pancreatic insufficiency present a higher risk of developing this complication. The decline in pulmonary function is more accelerated in glucose intolerant patients than in those with normal glycemic metabolism. The decreased survival and increased morbidity associated with CFRD make early diagnosis fundamental. Since the onset of the disease is often insidious, it is important that symptoms suggestive of CFRD, such as worsening of pulmonary function, significant weight loss, and worsening of overall health status, be noted. Microvascular complications are associated with the duration of the disease and glycemic control. The risk of macrovascular complications is low. Triage, using the OGTT, should be performed annually for patients from 6 to 10 years of age. Through this test, patients are classified as presenting normal glucose tolerance, being glucose intolerant, having CFRD with fasting hyperglycemia, or having CFRD without fasting hyperglycemia. Insulin therapy is the pharmacological approach of choice for CFRD with fasting hyperglycemia. Oral hypoglycemic agents are not indicated. Hypoglycemia and ketoacidosis are rarely observed. In these patients, multidisciplinary follow-up evaluations play a fundamental role in treatment compliance and clinical improvement.

\section{References}

1. Brennan AL, Geddes DM, Gyi KM, Baker EH. Clinical importance of cystic fibrosis-related diabetes. J Cyst Fibros. 2004;3(4):209-22.

2. Spence C. Cystic fibrosis-related diabetes: practice challenges. Paediatr Nurs. 2005;17(2):23-6.

3. Costa M, Potvin S, Berthiaume Y, Gauthier L, Jeanneret A, Lavoie A, et al. Diabetes: a major co-morbidity of cystic fibrosis. Diabetes Metab. 2005;31(3 pt 1):221-32.

4. Rozov T, Cunha MT, Nascimento 0, Quittner AL, Jardim JR. Validação lingüística dos questionários de qualidade de vida em fibrose cística. J Pediatr (Rio J). 2006;82(2):151-6.

5. Rosenstein BJ, Cutting GR. The diagnosis of cystic fibrosis: a consensus statement. Cystic Fibrosis Foundation Consensus Panel. J. Pediatr. 1998;132(4):589-95.

6. Alvarez AE, Ribeiro AF, Hessel G, Bertuzzo CS, Ribeiro JD. Cystic fibrosis at a Brazilian center of excellence: clinical and laboratory characteristics of 104 patients and their association with genotype and disease severity. J Pediatr (Rio J). 2004;80(5):371-9.

7. Mickle JE, Cutting GR. Clinical implications of cystic fibrosis transmembrane conductance regulator mutations. Clin Chest Med. 1998;19(3):443-58.

8. Hadjiliadis D, Madill J, Chaparro C, Tsang A, Waddell TK, Singer $\mathrm{LG}$, et al. Incidence and prevalence of diabetes mellitus in patients with cystic fibrosis undergoing lung transplantation before and after lung transplantation. Clin Transplant. 2005;19(6):773-8.

9. Marshall BC, Butler SM, Stoddard M, Moran AM, Liou TG, Morgan WJ. Epidemiology of cystic fibrosis-related diabetes. J Pediatr. 2005;146(5):681-7.

10. Lombardo F, De Luca F, Rosano M, Sferlazzas C, Lucanto C, Arrigo T, et al. Natural history of glucose tolerance, beta-cell function and peripheral insulin sensitivity in cystic fibrosis patients with fasting euglycemia. Euro J Endocrinol. 2003;149(1):53-9.

11. Lanng S. Glucose intolerance in cystic fibrosis patients. Pediatr Resp Rev. 2001;2(3):253-9.

12. Castellanos RB, Blanco AC, García EG, Cañadell MG, Torres JFM, Calvo MTM. Consensus on the diagnosis and management of changes in carbohydrate metabolism in cystic fibrosis. An Esp Pediatr. 2000;53(6):573-9.

13. Mackie AD, Thornton SJ, Edenborough FP. Cystic fibrosisrelated diabetes. Diabet Med. 2003;20(6):425-36.

14. Dobson L, Sheldon CD, Hattersley AT. Understanding cystic-fibrosis-related diabetes: best thought of as insulin deficiency. J R Soc Med. 2004;97 Suppl 44:S26-S35.

15. Jensen $P$, Johansen HK, Lanng $S$, Hoybi N. Relative increase in $\operatorname{lgG}$ antibodies to Pseudomonas aeruginosa $60-\mathrm{kDa}$ GroEL in prediabetic patients with cystic fibrosis. Pediatr Res. 2001;49(3):423-8.

16. Lanng S, Thorsteinsson B, Pociot F, Marshall MO, Madesen HO, Schwartz M, et al. Diabetes mellitus in cystic fibrosis: genetic and immunological markers. Acta Paediatr. 1993;82(2):150-4.

17. Moran A. Diagnosis, screening and management of cystic fibrosis-related diabetes. Curr Diab Rep. 2002;2(2):111-5.

18. Moran A, Diem P, Klein DJ, Levitt MD, Robertson RP. Pancreatic endocrine function in cystic fibrosis. J Pediatr. 1991;118(5):715-23.

19. Moran A, Milla C. Abnormal glucose tolerance in cystic fibrosis: Why should patients be screened? J Pediatric. 2003;142(2):97 -9.

20. Castro FA, Fernandes Ml, Junior RM, Foss MC. Study of the frequency of diabetes mellitus and glucose intolerance in patients with cystic fibrosis. J Pediatr (Rio J). 2001;77(4):321-6.

21. Hotamisligil GS, Shargill NS, Spiegelman BM. Adipose expression of tumor necrosis factor-alfa: direct role in obesitylinked insulin resistance. Science. 1993;259(5091):87-91.

22. Ofei F, Hurel S, Newkirk J, Sopwith M, Taylor R. Effects of an engineered human anti-TNF-alfa antibody (CDP571) on insulin sensitivity and glycemic control in patients with NIDDM. Diabetes. 1996;45(7):881-5.

23. Hardin DS, Leblanc A, Marshall G, Seilheimer DK. Mechanism of insulin resistance in cystic fibrosis. Am J Physiol Endocrinol Metab. 2001;281(5):E1022-8.

24. Hardin DS, Moran A. Diabetes mellitus in cystic fibrosis. Endocrinol Metab Clin North Am. 1999;28(4):787-800, ix.

25. Milla CE, Warwick WJ, Moran A. Trends in pulmonary function in patients with cystic fibrosis correlate with the degree of glucose intolerance at baseline. Am J Resp Crit Care Medicine. 2000;162(3 Pt 1):891-5.

26. Lanng S, Thorsteinsson B, Nerup J, Koch C. Diabetes mellitus in cystic fibrosis: effect of insulin therapy on lung function and infections. Acta Paediatrica. 1994;83(8):849-53.

27. Rozov T. Mucoviscidose (Fibrose Cística do Pâncreas). In: Rozov T, editor. Doenças Pulmonares em Pediatria. São Paulo: Atheneu; 1999. p. 443-59. 
28. Moran A. Endocrine complications of cystic fibrosis. Adolesc Med. 2002;13(1):145-59, vii-viii.

29. Rafii M, Chapman K, Stewart C, Kelly E, Hanna A, Wilson DC, et al. Changes in response to insulin and the effects of varying glucose tolerance on whole-body protein metabolism in patients with cystic fibrosis. Am J Clin Nutr. 2005;81(2):421-6.

30. Azzopardi K, Lowes L. Management of cystic fibrosis-related diabetes in adolescence. Br J Nurs.2003;12(6):359-63.

31. Solomon MP, Wilson DC, Corey M, Kalnins D, Zielenski J, Tsui LC, et al. Glucose intolerance in children with cystic fibrosis. J Pediatr. 2003;142(2):128-32.

32. Scott Al, Clarke BE, Healy H, D Emen M, Bell SC. Microvascular complications in cystic fibrosis-related diabetes: a case report. JOP. 2000;1(4):208-10.

33. Dobson L, Stride A, Bingham C, Elworthy S, Sheldon $\mathrm{CD}$, Hattersley AT. Microalbuminuria as a screening tool in cystic fibrosis-related diabetes. Pediatr Pulmonol. 2005;39(2):103-7.

34. Milla CE, Billings J, Moran A. Diabetes is associated with dramatically decreased survival in female but not male subjects with cystic fibrosis. Diabetes Care. 2005;28(9):2141-4.
35. Lombardi F, Raia V, Spagnuolo Ml, Nugnes R, Valério G, Ciccarelli G, et al. Diabetes in an infant with cystic fibrosis. Pediatric Diabetes. 2004;5(4):199-201.

36. Dobson L, Hattersley AT, Tiley S, Elworthy S, Oades PJ, Sheldon CD. Clinical improvement in cystic fibrosis with early insulin treatment. Arch Dis Child. 2002;87(5):430-1.

37. Starkman F, Das S. Cystic fibrosis presenting as new onset diabetes mellitus in adolescent twins. Pediatr Diabetes. 2004;5(2):99-101.

38. Gilljam M, Ellis L, Corey M, Zielenski J, Durie P, Tullis E. Clinical manifestations of cystic fibrosis among patients with diagnosis in adulthood. Chest. 2004;126(4):1215-24.

39. Moran A, Phillips J, Milla C. Insulin and glucose excursion following pre-meal insulin lispro or repaglinide in cystic fibrosis-related diabetes. Diabetes Care. 2001;24(10):1706-10.

40. Mueller-Brandes C, Holl RW, Nastoll M, Ballmann M. New criteria for impaired fasting glucose and screening for diabetes in cystic fibrosis. Eu Respir J. 2005;25(4):715-17.

41. Moran A. Cystic fibrosis-related diabetes: an approach to diagnosis and management. Pediatr Diabetes. 2000;1(1):41-8. 